University of Massachusetts Amherst ScholarWorks@UMass Amherst

Communication Department Faculty Publication

Series

Communication

2017

\title{
Cultivating Conceptions of Masculinity: Television and Perceptions of Masculine Gender Role Norms
}

Erica Scharrer

University of Massachusetts Amherst

Greg Blackburn

University of Massachusetts Amherst

Follow this and additional works at: https://scholarworks.umass.edu/communication_faculty_pubs Part of the Mass Communication Commons

\section{Recommended Citation}

Scharrer, Erica and Blackburn, Greg, "Cultivating Conceptions of Masculinity: Television and Perceptions of Masculine Gender Role Norms" (2017). Mass Communication and Society. 46.

https://doi.org/10.1080/15205436.2017.1406118

This Article is brought to you for free and open access by the Communication at ScholarWorks@UMass Amherst. It has been accepted for inclusion in Communication Department Faculty Publication Series by an authorized administrator of ScholarWorks@UMass Amherst. For more information, please contact scholarworks@library.umass.edu. 


\title{
Cultivating conceptions of masculinity: Television and perceptions
}

\section{of masculine gender role norms}

\author{
Erica Scharrer \\ University of Massachusetts, Amherst, USA \\ Florence, USA \\ Greg Blackburn
}

Communication, Integrative Learning Center, University of Massachusetts Amherst, North Pleasant Street, Amherst, USA

Correspondence should be addressed to Erica Scharrer E-mail: scharrer@comm.umass.edu

Abstract

The potential of television to both reflect and shape cultural understandings of gender roles has long been the subject of social scientific inquiry. The present study employed survey methodology with 420 emerging adult respondents (aged 18 to 25 ) in a national U.S. sample to explore associations between amount of time spent viewing television and views about "ideal" masculine gender roles. The viewing of particular television genres was explored in addition to (and controlling for) overall amount of time spent with the medium, using cultivation theory as the theoretical foundation. Results showed significant statistical associations between viewing sitcoms, police and detective programs, sports, and reality television and scores on the Masculine Roles Norms Inventory-Revised scale. Biological sex of respondent (which very closely approximated gender identity in the sample) moderated a number of these relationships, with positive associations between viewing some genres and endorsement of traditional masculine gender roles stronger for biological male compared to biological female respondents. 
Keywords: cultivation theory, television, genre, gender, masculinity

Television use has been associated with holding more stereotypical views of gender norms and roles (Oppliger, 2007). Yet, many of the studies that have examined television viewing and its association with attitudes toward gender roles are now quite outdated (e.g. Morgan, 1982; Signorielli, 1989). This study joins a small number of recent quantitative explorations of media's potential to contribute to conceptions of masculinity, in particular (e.g., Giaccardi, Ward, Seabrook, Manago \& Lippman, 2016, 2017). Endorsement of narrowly traditional views of masculinity has been associated with a host of negative outcomes including sexual aggression, tolerance for sexual harassment, prejudice against women and racial minorities (Levant \& Richmond, 2007), and heightened risk behavior (Giaccardi et al., 2017). Thus, the ability of television viewing to shape and/or to reflect views of masculine gender role norms is a socially significant topic worthy of inquiry.

\section{Literature Review Cultivation theory: Overall television use, particular genres, and views of gender role norms}

Cultivation theory (Gerbner \& Gross, 1976) offers a theoretical lens through which we can view the association between television use and individuals' outlooks on masculinity. Briefly stated, cultivation theory posits that television content provides consistent message patterns that construct a specific perspective on social reality. Those who spend more time with television are more likely to reflect those perspectives in their own views compared to those who spend less time (Morgan, 2009). In other words, the message system of television programming, in which particular stories are privileged over others and in which distinct patterns emerge from stable content features, can shape viewer outlooks regarding the world around them, so that "television reality" becomes a source of information 
about social reality (Signorielli, 2009).

Perceptions of social reality are distinguished as either first-order or second-order judgments, with the former defined as estimates of the frequency of some aspect of social order (like the number of violent crimes that take place) and the latter having to do with values, attitudes, and beliefs (like whether viewers perceive the world pessimistically; Morgan, Shanahan \& Signorielli, 2012). An important difference, then, is whether there is a direct comparison available between the world as portrayed on television and the real world (as is the case for first-order judgments) or whether the relationship between the television world and the real world must be inferred, as is the case of second-order judgments (Schnauber \& Meltzer, 2016; Shrum, 2004; Shrum \& Lee, 2012). There is evidence that these two types of judgments engage differential processing strategies, with second-order judgments generally conceived as online judgments made spontaneously as information is encountered during television viewing, relying less heavily on memory accessibility than first-order judgments (Shrum \& Lee, 2012). Online judgments are more likely to occur if individuals are motivated to make them, for instance by a perceived relevance to their lives, involvement with the topic, or perception of the topic as important (Schnauber \& Meltzer, 2016).

Cultivation researchers have also found evidence of a pattern known as mainstreaming, where heavy viewers of television converge around a shared outlook (often a second-order judgment) despite differences in their backgrounds, whereas light viewers' outlooks on the subject diverge (Gerbner, Gross, Morgan, \& Signorielli, 1980). The message system provided by television, therefore, can overcome differences in outlook one might expect based on individual differences (Gerbner et al., 1980). Somewhat conversely, a phenomenon called resonance occurs when the cultivation effect is magnified among those whose real-life experiences mirror the content presented on screen (Gerbner et al., 1980). In this case, the views of the social world among subgroups with different backgrounds or experiences 
would diverge instead of converge. For example, heavy viewers from high crime neighborhoods tend to think of the world as more violent compared to heavy viewers from low crime neighborhoods (Shrum \& Bischak, 2001). Despite early critique that these phenomena were explained post-hoc by cultivation researchers (Hirsch, 1981), the concepts remain active in contemporary cultivation findings (Morgan, Shanahan, \& Signorielli, 2015; Potter, 2014).

Critique of cultivation theory also questioned whether television's message system was as coherent and consistent across genres (types of programming categories, such as dramas, sitcoms, or news programs) as originally assumed by cultivation theorists (Potter, 2014). As television viewing technologies changed to include ways of customizing content for viewers, the idea that viewers were experiencing more or less the same basic features of television content regardless of what programs they watched became the subject of heightened critique. Researchers began to explore whether more narrow categories or types of television exposure might also cultivate viewers' outlooks on life (Potter, 1993).

The viewing of specific genres or program types has, indeed, been found to predict a number of cultivation outcomes (e.g., Bilandzic \& Rössler, 2004; Cohen \& Weimann, 2000). Bilandzic and Busselle (2012) argue that the viability of a genre-based explanation for cultivation hinges on whether audiences expect a particular experience from the genre and whether, relatedly, the content patterns within the genre reflect a relatively stable set of themes. Yet, Morgan and colleagues (2015) suggest that 'although the way we now receive our 'stories' (whether fiction, news, or reality programs) has changed...we tend to forget that important aspects of their content arguably have not” (p. 685), arguing that the implications of television viewing in totality are still relevant in today's media environment. Lessons about gender are among those that Morgan and colleagues characterize as "remarkably persistent" across multiple types of television programming (p. 686). Nonetheless, they acknowledge that to the extent that genres are "a source of consistent ideological messages," genre-specific cultivation 
can actually comply with the theory's original "notions of television's institutional role as a source of consistent cultural stories" (p. 690). A genre-specific view of cultivation theory can be advanced, therefore, using the same prevailing logic of consistent meta-level messages on which the theory has long been based (Morgan et al., 2015). Morgan and colleagues (2015) suggest bringing the two approaches to cultivation together, exploring genres alongside overall viewing to account for the likelihood that even ardent fans of a genre are likely to watch programs outside of that genre, as well.

Conceptions and endorsements of gender role norms are second-order cultivation judgments, as they represent attitudes and values, and prior research has, indeed, linked such conceptions with television viewing (Kahlor \& Morrison, 2007). In a meta-analysis, Morgan and Shanahan (1997) found a small but significant role for television use in the cultivation of stereotypical conceptions of gender roles. Exposure to specific television genres has also been associated with views about the ways in which roles are or should be distributed by gender in the real world (Kahlor \& Morrison, 2007). Cultivation theory has traditionally examined questions of power, privilege, and position in social structures (Gerbner, 2002a, 2002b) and has been put forth as a bridge between media effects theories and critical cultural and feminist approaches to media studies (Ruddock, 2001).

\section{Television and masculinity: General patterns}

Modern conceptions of masculinity recognize it as socially constructed, multidimensional, and variable (Levant \& Richmond, 2007), recast as it intersects with race, class, sexuality and other components of identity (Kimmel, 1987). Although cultural ideals of masculinity shift to suit a given historical moment (Connell, 2005), there remain a number of core beliefs, attitudes, and behaviors associated with traditional masculine roles (Levant \& Richmond, 2007). Drawing from Antonio Gramsci and taken up in feminist and critical theory, hegemonic masculinity identifies common sense understandings and dominant ideologies that reify gender hierarchies (Connell \& Messerschmidt, 2005; 
Gramsci, 1971; Hanke, 1992). Common features of traditional masculinity (a concept similar to hegemonic masculinity) include avoidance of femininity, dominance, importance of sex, restrictive emotionality (suppressing the expression of emotions), negativity toward sexual minorities, and selfreliance (Levant, Smalley, Aupont, House, Richmond et al., 2007).

Measuring beliefs about "sexual minorities," however, fails to distinguish among gay men, lesbian women, those identifying as bisexual, or those with additional non-dominant sexual identities toward whom individuals can have varying views (Chonody, 2013). Prior research has suggested that heterosexual men scoring higher on a measure of hypermasculinity — an exaggerated view of masculinity with many of the same features as "traditional" or hegemonic masculinity—had more prejudiced views of gay men, in particular, compared to those scoring lower in hypermasculinity (Barron, Struckman-Johnson, Quevillon, \& Banka, 2008). Attitudes toward and beliefs about gay men, therefore, appear to be particularly salient aspects of various outlooks on masculinity(ies).

Content analyses have explored depictions related to many of these dimensions of masculinity among television's broad message system, as seen in studies of primetime television content that span multiple genres and the commercials placed within. Roles on television are delineated in part through a division between the professional and domestic spheres. Men's roles have primarily emphasized out-ofthe-home employment (Lauzen, Dozier, \& Horan, 2008; Signorielli, 2009). In the most recent content analysis of U.S. primetime television, women characters were coded as significantly more "family oriented" than men characters (Sink \& Mastro, 2017). In television commercials across multiple genres, depictions of men engaged in parenting and other domestic responsibilities have been found to be infrequent (Fowler \& Thomas, 2015; Verhellen, Dens, \& de Pelsmacker, 2016) and, when present, often depicted negatively (Scharrer, Kim, Lin, \& Liu, 2006). Prieler (2016) found that women appeared in the home more often than men in both English and Spanish-language commercials in the United States, and 
men appeared at work more often in English language commercials.

Content analyses indicate that character attributes portrayed on television fit many aspects of traditional masculinity outlined by Levant and colleagues (2007), as well. In terms of aggression, men are more likely than women on television to be the perpetrators of physical aggression (Signorielli, 2003; Sink \& Mastro, 2017), verbal aggression, bullying, and dominance (Sink \& Mastro, 2017). Sexual harassment of women by men is depicted on television, as well, largely through demeaning and objectifying language (Grauerholz \& King, 1997; Ward, 2003). In terms of relationship orientation, men are less often depicted in family, friend, and romantic interactions on primetime television compared to women (Lauzen, Dozier, \& Horan, 2008). In terms of heteronormativity, representations of gay men have shifted somewhat, with the general pattern of nonrepresentation and ridicule that marked the first decades of television gradually giving way to somewhat more positive roles (Bond, 2014; Raley \& Lucas, 2006). Yet, there is evidence that negative stereotypes of gay men persist on television (Bond, 2014; Fisher, Hill, Grube, \& Gruber, 2007). The bulk of the evidence, therefore, points to rather narrow roles for male characters within television content broadly sampled, with indicators of many of the dimensions of a traditional masculinity that Levant and colleagues (2007) define.

Despite these patterns in television content, the evidence for corresponding associations with viewer outlooks is mixed. Rivadeneyra and Ward (2005) found, among a sample of 186 Latino high school students, that overall amount of television viewing was not associated with boys' attitudes regarding male dominance in relationships. Calzo and Ward (2009) found no evidence of association between oyerall amount of viewing and attitudes toward homosexuality among their sample as a whole. Yet, they did find that among highly religious respondents, amount of viewing was a positive predictor and among those scoring low in religiosity, amount of viewing was a negative predictor of support for homosexuality. They interpret this finding as evidence of the concept of mainstreaming, in that 
television use helped the outlooks of those differing by religiosity to converge around shared support for same sex relationships. Other studies have identified important differences by respondents' gender in associations between overall TV viewing and holding gender stereotypes regarding sexual and romantic roles, in particular (Ter Bogt et al., 2010, Vandenbosch \& Eggermont, 2012). Giaccardi and colleagues (2016, 2017) provide the closest parallels to the study at hand. Using cultivation theory as the theoretical lens, they tested the ability of overall television viewing and the viewing of particular television genres to shape conceptions of masculine gender roles among college males. The researchers found significant bivariate correlations between overall amount of TV viewing and endorsement of traditional views of masculinity as well as with one's own conformity to such norms (Giaccardi et al., 2016, 2017), but the associations disappeared when controlling for sexual orientation and age in hierarchical regressions (Giaccardi et al., 2016). We can conclude, on the basis of all of the prior studies in this topic area, that the broad message system supplied by television can interact with individual differences of viewers to predict outlooks regarding aspects of masculine gender roles.

\section{Masculinity and television genres}

There is some evidence that depictions of masculine gender roles on television vary by genre, as do the implications of such depictions. Sitcoms have been shown to utilize many tropes of traditional masculinity, but also have the potential to counter masculine gender stereotypes through emotional expression by male characters and other indicators of sensitivity (Feasey, 2008; Zimdars, 2017). Content analyses of male characters on sitcoms have identified foolish and inept fathers (Scharrer, 2001) in addition to sexual dominance and harassment by males (Kim, Sorsoli, Collins, Zylbergod, Schooler et al., 2007; Montemurro, 2003). In terms of effects, a study of heterosexual couples expecting a child found exposure to TV programs featuring father characters (which included, but was not limited to, sitcoms) was associated with a tendency to hold less egalitarian views of gender roles in the family (Kuo 
\& Ward, 2016). Yet, Ward and Friedman (2006) found that exposure to "sexy content" on primetime (that included both sitcoms and dramas) was not associated with a belief that men are driven by sexual desire. Viewing one particular sitcom (Will and Grace) was associated with holding less prejudiced views of gay men in one study (Schiappa, Gregg, \& Hewes, 2006), and in another, sitcom viewing, in general, predicted support for homosexuality among those high in religiosity (Calzo \& Ward, 2009). Most recently, exposure to a gay male character in the sitcom Happy Endings led to an increase in negative attitudes toward gay men, with both gender and political ideology moderating the effect (Miller \& Lewallen, 2015).

On police and detective drama programs, Finger, Unz, and Schwab (2010) found evidence of depictions of restrictive and aggressive emotionality, as male characters displayed anger and contempt more than their female counterparts and showed sensitive emotions less often. Scharrer (2012) found a trend toward greater emotional expressiveness among male characters on police and detective programs from the 1950s to the 1980s, but then a return to more stoicism in the 1990s. Male characters were also shown to be frequently depicted using physical aggression and violent behavior in police and detective programs (Parrott \& Parrott, 2015; Scharrer, 2012). In dramas, in general, Kim et al. (2007) found that narratives featuring male dominance over women were present, and Lauzen and Dozier (2002) reported that men frequently used verbal insults to emotionally distance themselves from other men. Exposure to a televised drama was found to spur an increase in college males' conformity to the dimension of hypermasculinity that associates masculinity with violence in an additional prior study (Scharrer, 2005). Ferris, Smith, Greenberg, and Smith (2007) conducted a content analysis of reality television dating shows, finding that the men regularly objectified women and often appeared to be driven by sex. In a corresponding survey of 197 undergraduates, they found viewing this subgenre of reality TV was correlated with endorsement of related attitudes. Viewing romantic-themed reality TV shows has been 
associated with holding gendered attitudes toward dating in additional studies, as well (Rivadeneyra \& Lebo, 2008, Zurbriggen \& Morgan, 2007). Among college males, Giaccardi and colleagues $(2016,2017)$ found that viewing reality TV was a significant predictor of adherence to traditional views of males in interpersonal relationships (as measured by the Adolescent Masculinity in Relationships Scale, with items pertaining to the suppression of emotions, the display of sexual drive, and the importance of appearing tough) as well as with respondents' own levels of conformity with masculine norms. In televised sports, male athletes have been argued to be presented as models of traditional masculinity, marked by aggression, strength, and competitive drive (Feasey, 2008). Sports viewing has been found to be negatively correlated with beliefs about gender equality (Dutta-Bergman \& DuttaBergman, 2005) and, for men, with willingness to intervene against sexual assault (Hust, Lei, Ren, Chang, McNab, et al., 2013). In additional studies, sports viewing was positively correlated with endorsement of and conformity to traditional masculine norms among men (Giaccardi et al., 2016, 2017; Johnson \& Schiappa, 2010) and with rape myth acceptance among women (Hust et al., 2013).

We can conclude on the basis of the available content analysis evidence that depictions of masculinity have the potential to differ by genre. Yet, within each of the genres reviewed here, there is at least some indication of particular stereotypical roles and behaviors assigned to male characters. From the prior evidence from effects studies, it appears that viewing television genres is linked with several indicators of traditional masculinity, especially for sports and reality TV viewing. In some cases, individual differences (like gender, political ideology, or religiosity) shape these patterns.

The current study expands upon the foundation provided by Giaccardi and colleagues (2016, 2017), in particular, in three ways. First, it explores conceptions of masculinity in relation to television viewing among both men and women rather than just among men. Given that prior research has suggested that women tend to have more fluid views of gender compared to men (Smiler \& Gelman, 
2008), testing whether women's views of masculinity as well as men's correlate with television viewing is an important inquiry. Second, the current study adds police and detective programs and sitcoms to the particular genres of television explored for their ability to predict masculine gender role norms. Given the long-standing presence of those additional genres on the television programming schedule (Arntfield, 2011; Lieberman, Neuendorf, Denny, Skalski, \& Wang, 2009), these are important new genres to analyze. Third, the present study uses a national sample rather than a college sample, thereby reflecting wider education levels and a broader age range in addition to greater geographical diversity. It is important to determine whether the patterns discovered by Giaccardi and colleagues $(2016,2017)$ will be apparent in the present, more heterogeneous sample.

\section{Hypotheses and Theoretical Linkages}

The ability of overall amount of television viewing to cultivate conceptions of masculine gender role norms rests, in part, on the establishment of a message system with stable features regarding the depiction of masculine gender roles, a condition that prior content analyses suggest has largely been met. Cultivation theory predicts that heavy viewers will be more likely than light viewers to make secondorder judgments, inferring from television's message system to the formation of their own attitudes and values (Kahlor \& Morrison, 2007; Morgan et al., 2012; Schnauber \& Meltzer, 2016; Shrum \& Lee, 2012). In the first hypothesis, we extend from the Giaccardi et al. $(2016,2017)$ research that found bivariate correlations between overall amount of television viewing and endorsement of traditional masculine gender norms among males to explore the same question among both males and females: Hla: The more time spent with television, the greater the endorsement of a traditional view of masculinity.

On the other hand, television exposure has the potential to promote a more accepting view of same-sex sexuality through positive depictions in overall programming (Bond, 2014; Calzo \& Ward, 
2009; Raley \& Lucas, 2006). Therefore, we predict that heavy viewers will be more likely than light viewers to express a second-order judgment that corresponds to this feature of television's broad message system, and we apply the principle to views of gay men, in particular:

H1b: The more time spent with television, the lower the endorsement of the negativity toward gay men component of traditional masculinity.

The literature review identifies particular depictions of masculinity within particular genres of television that appear to be rather consistent within each genre, thereby meeting the criterion advanced by Busselle and Bilandzic (2012) to explore a genre-specific explanation for cultivation theory. On the basis of genre-specific cultivation theory and the features of the genre-specific message system we have reviewed, we make a series of predictions regarding genre viewing and second-order judgments pertaining to perceptions of particular aspects of masculine gender role norms. We build on the foundation provided by Giaccardi et al $(2016,2017)$ to examine associations with sports and reality television viewing and extend beyond that work to include police and detective programs and sitcoms on the basis of the prior content analysis evidence and due to the enduring prominence of those genres (Arntfield, 2011; Lieberman et al., 2009).

H2: The more time spent with policeldetective programs, the greater the endorsement of traditional masculinity, particularly regarding the restrictive emotionality, avoidance of femininity, toughness, and aggression components.

H3: The more time spent with sports programming, the greater the endorsement of traditional masculinity.

H4: The more time spent with reality television, the greater the endorsement of traditional masculinity, particularly regarding the importance of sex and the dominance components.

H5a: The more time spent with sitcoms, the greater the endorsement of traditional masculinity for the 
components of avoidance of femininity and the importance of sex.

H5b: The more time spent with sitcoms, the lower the endorsement of traditional masculinity for the components of negativity toward gay men and restriction of emotionality.

Given that second-order judgments are more likely to occur if there is perceived relevance to or involvement with the topic (Schnauber \& Meltzer, 2016; Shrum \& Lee, 2012), and given the pattern detected in prior research (Giaccardi et al., 2016, 2017; Scharrer, 2005) we expect perceptions of masculine gender role norms will be more salient for the male respondents in the study. In the language of cultivation theorists (Gerbner et al., 1980), then, we predict resonance for the men in the sample: H6: Associations between television viewing and endorsement of a traditional view of masculinity will be stronger for male respondents compared to female respondents.

\section{Method}

\section{Sample and Procedure}

After obtaining Human Subjects Review approval from the authors' home university's Institutional Review Board in March, 2015, a cross-sectional survey was conducted, with participants recruited by Qualtrics using its national panel of research participants. Qualtrics aggregates nationally representative panels and randomly selects from its database of participants for any study. In the present case, we asked for an equal number of self-identified males and females between the ages of 18 and 25 with racial and ethnic (Latino/non-Latino) characteristics that parallel the national population in the United States. That age range was chosen to reflect the period of emerging adulthood, which prior research has established as a critical time for masculine gender role construction (Marcell, Eftim, Sonenstein, \& Pleck, 2011). All individuals in the Qualtrics database meeting the criteria were invited to participate by random selection. From among those tens of thousands, individuals completed the survey until the quota of 420 valid responses was met. 
Participants were informed that they would complete an online survey on attitudes and social beliefs, and informed consent was obtained via an online form. The surveys began with measurement of the masculinity-related variables, followed by a section measuring personality variables included only to mask the purpose of the study. Finally, measures of media use and demographic information were collected. Attention check items were embedded and if respondents failed to answer those correctly, their data were discarded. Following completion, participants received a debriefing message.

An a priori power analysis was conducted using $\mathrm{G}^{*}$ Power. Previous meta-analyses of television's association with gender roles have found average effects sizes of .10 to .12 (Morgan \& Shanahan, 1997; Oppliger, 2007). To detect effects of that size for the current study, using a Bonferonicorrected $\alpha$ error probability of .0045 and a .80 level of power, a total sample size of at least 202 participants was determined to be necessary. We obtained 420 valid responses, more than twice that number. In the sample, in terms of biological sex, 210 respondents reported they were assigned male at birth and 210 reported they were assigned female. In terms of gender, 210 respondents identified as male, 208 as female, and 2 as transgender. Thus, there was a close correspondence between biological sex and gender identity in the sample. Rather than discard the data from the two transgender respondents to study differences only among those with male and female gender identity, to ensure all respondents' views were represented, subsequent analyses used the biological sex variable to test differences between those assigned male and female at birth where relevant.

Participants ranged in age from 18 to 25 , with a mean age of 21.65 years $(S D=2.32)$. We asked respondents their sexual orientation, and $89.3 \%$ reported they were straight or heterosexual $(n=375)$, $3.3 \%$ gay or lesbian $(n=14), 6.4 \%$ bisexual $(n=27)$, and $1.0 \%$ other $(n=4)$. We also measured race/ethnicity, with $62.1 \%$ reporting White $(n=261), 12.4 \%$ Black or African American $(n=52), 14.5 \%$ Latino or Hispanic $(n=61), 6.0 \%$ Asian or Asian American $(n=25), 4.0 \%$ multi- or biracial $(n=17)$, 
and $1.0 \%$ other $(n=4)$. Again, this distribution was designed in the sampling process to reflect the U.S. population. Respondents' highest level of education was measured, with $42.9 \%$ reporting some college $(n=180), 23.8 \%$ reporting they were high school graduate $(n=100), 17.1 \%$ having obtained a Bachelor's or other four-year degree $(n=72), 8.3 \%$ an Associate's or other two-year degree $(n=35)$, $4.3 \%$ a graduate or professional degree past Bachelor's $(n=18)$, and 3.6\% having had some high school or less $(n=15)$. Total household income was reported by $15.0 \%$ of the sample as falling between $\$ 20,000$ and $\$ 29,999$ per year $(n=63), 14.0 \%$ between $\$ 30,000$ to $\$ 39,999(n=59)$, and $12.1 \%$ between $\$ 50,000$ to $\$ 59,999(n=51)$. The annual household income of the remainder of the sample was distributed widely across each of the options that ranged from under $\$ 10,000$ a year (reported by $7.6 \%$ of the sample, $n=32)$ to over $\$ 150,000(3.6 \%, n=15) .9 .5 \%$ of the sample reported they did not know their total household income $(n=40)$.

\section{Measures}

Endorsement of traditional masculinity. The Masculine Roles Norms Inventory- Revised (MRNI-R) was used to measure participants' endorsement of traditional masculine gender role norms (Levant et al., 2007). The index has been tested for internal consistency, as well as concurrent and convergent validity (Levant, Rankin, Williams, Hasan \& Smalley, 2010) and features 39 items, each measured from 1 (strongly disagree) to 7 (strongly agree). Higher scores indicate stronger endorsement of more traditional masculine gender roles and norms. A composite measure for the index was formed in which the items comprising each of the 7 components (weighted by the number of items within each component) were added together and then averaged for ease of interpretation. This measure, the MRNI$\mathrm{R}$ as a whole, had a Cronbach's $\alpha$ of .97.

Seven subscales are contained within the overall measure, and prior research has found that each is a unique dimension of the overall scale (Levant et al., 2010) ${ }^{1}$. The subscales are avoidance of 
femininity (e.g., "Boys should play with action figures not dolls;" "Men should not wear cover-up, make-up, or bronzer;" Cronbach's $\alpha=.93$ ); toughness (e.g., "I think a young man should try to be physically tough, even if he's not big;" "It is important for a man to take risks, even if he might get hurt;" Cronbach's $\alpha=.82$ ); dominance ("A man should always be the boss;" "Men should provide the discipline in the family;" Cronbach's $\alpha=.92$ ); importance of sex ("Men should always like to have sex;" "A man should always be ready for sex;" Cronbach's $\alpha=.89$ ); restrictive emotionality (e.g., "A man should not react when other people cry;" "Fathers should teach their sons to mask fear;" Cronbach's $\alpha=$ .89), and self-reliance (e.g., "Men should have home improvement skills," "A man should know how to repair his car if it should break down;" Cronbach's $\alpha=.88$ ). An additional component was called negativity toward sexual minorities by Levant and colleagues (2010) and some of the items measuring that component used the word "homosexual." Yet, given that the term homosexual can carry a pejorative connotation and fails to distinguish between gay men and lesbian women (Chonody, 2013), those items were modified slightly to replace the term "homosexuals" with "gay" or "gay man" in relevant items and the component was renamed negativity toward gay men for the current study. We also added the modifier "male" when referencing a hypothetical famous athlete in one particular item. Sample items include "Gay men should never kiss in public" and "It is disappointing to learn that a famous male athlete is gay;" and the Cronbach's $\alpha$ was .95.

Because the Toughness component of the MRNI-R does not feature a strong emphasis on physical aggression, we also used one subscale (five items) from the Auburn Differential Masculinity Index (ADMI; Burk, Burkhart \& Sikorski, 2004) to measure perceptions about masculinity and its connection to aggression and physical violence. In order to match the MRNI-R items, we changed the wording slightly so that the selected ADMI items inquired about respondents' perceptions of norms rather than their own personal adherence to norms. Sample items include, "Sometimes a man's got to 
fight or people will walk all over him." and "It's OK for a man to use physical violence to defend what he has," and responses ranged from 1 (strongly disagree) to 7 (strongly agree), Cronbach's $\alpha=.85$.

Television exposure. Overall television exposure was measured by asking respondents how many hours of TV they watch on each day of the week, respectively, and averaging across each of those daily estimates to come up with an overall measure of television exposure per day. Research shows that asking respondents to estimate television exposure on a typical weekday and on a typical weekend has sufficient validity and reliability and correlates with time spent viewing as measured with diaries (Greenberg et al., 2005). In the current study, specific days of the week were used in the television exposure measure to allow for greater precision and to attempt to avoid the recall bias that can threaten more global measures (Robinson \& Godbey, 1997). Respondents were asked to include broadcast, cable, satellite, online-streaming (e.g., Netflix, Hulu), and DVD collections in their estimate, in response to Morgan, Shanahan and Signorielli's (2015) suggestions for accounting for newer means of accessing television content. Consistent with prior genre-based cultivation research (e.g., Bilandzic \& Busselle, 2008), exposure to particular genres was measured by asking respondents to indicate on a 7-point scale (never to very often) how frequently they watch sports programming, police shows, sitcoms, and reality TV in addition to other genre viewing listed only to disguise intent. The following examples were listed parenthetically to make sure the genres were understood: police shows (e.g., CSI, Law \& Order), sitcoms (e.g., The Big Bang Theory, Modern Family), reality TV (e.g., Survivor, Keeping Up with the Kardashians), and sports programming (e.g., Monday Night Football, SportsCenter, WWE).

Given the number of hypotheses put forward and therefore the large number of statistical tests run, the Benjamini-Hochberg procedure was used to control the false discovery rate in the data analysis (Benjamini, \& Hochberg, 1995). Setting the initial significance level at $\alpha=.05$, the procedure indicated 
the null hypotheses should be accepted in tests above the critical value $p=.019$. Accordingly, only tests where $p<.019$ were considered significant in the analyses.

\section{Results}

\section{Television use}

Respondents reported a mean of 3.23 hours $(S D=3.65)$ of daily television viewing. Average scores for the genre exposure measures (again, measured from $1=$ never to $7=$ very often) were: sports $M=3.24(S D=2.21)$, police and detective programs $M=3.58(S D=1.95)$, sitcoms $M=4.25(S D=$ 1.94), and reality TV $M=3.23(S D=2.059)$. Independent samples t-tests indicated no significant differences between biological male and female respondents in average exposure for overall television, police and detective program, or sitcom viewing. For sports $(t[416]=8.57, p<.001)$, biological males $(M=4.09, S D=2.27)$ watched more often than biological females $(M=2.38, S D=1.77)$. For reality TV $(t[416]=-4.00, p<.01)$, biological females $(M=3.63, S D=2.14)$ watched more often than biological males $(M=2.84, S D=1.90)$.

\section{Correlation analyses}

H1a predicted that overall amount of television exposure would be positively correlated with endorsement of traditional masculine gender roles. Overall viewing was not correlated with the MRNI$\mathbf{R}$ in the data, $r=.08, n s$, and also was not correlated with the aggression and physical violence component of the ADMI, $r=.06, n s$. Therefore, H1a was rejected. H1b predicted that overall amount of viewing would predict less negativity (i.e., more positivity) toward gay men. The data showed a lack of an association between overall television exposure and the negativity toward gay men component of the MRNI-R $(r=.04, n s)$, resulting in a rejection of $\mathrm{H} 1 \mathrm{~b}$.

The next set of analyses tested associations with particular television genres, and controlled for 
overall amount of television viewing in order to isolate the independent association of the genre itself with the MRNI-R items (see Table 1). H2 predicted that amount of viewing of the police/detective genre would be positively associated with endorsement of traditional masculine gender roles. The hypothesis was partially supported, in that police/detective genre viewing was significantly associated with the MRNI-R as a whole $(r=.12, p=.014)$, as well as with the individual restrictive emotionality $(r=.14$, $p=.005)$, and toughness $(r=.13, p=.006)$ components of the MRNI-R and the aggression and physical violence component of the ADMI $(r=.14, p=.004)$. Yet, viewing the police and detective genre did not reach statistical significance in its association with the avoidance of femininity component of the MRNI-R $(r=.09, n s)$.

Table 1 about here

H3 predicted that amount of viewing of sports programming would be positively associated with endorsement of traditional masculine gender roles. Amount of viewing of sports programming on television was significantly associated with the MRNI-R in the data, $r=.35, p<.001$, in addition to the aggression and physical violence component of the ADMI, $r=.31, p<.001$, in support of $\mathrm{H} 3$.

H4 predicted that amount of viewing of reality television would be positively associated with endorsement of traditional masculine gender roles, particularly for the importance of sex and dominance components. H4 was partially supported. Amount of viewing of reality television was not significantly associated with the MRNI-R as a whole $(r=.10, n s)$ nor with the aggression and physical violence component of the ADMI $(r=.00, n s)$. Yet, viewing reality television was correlated with the importance of $\operatorname{sex}(r=.12, p=.015)$ and dominance $(r=.14, p=.004)$ components.

H5a predicted that amount of viewing of sitcoms would be positively correlated with 
endorsement of the importance and sex and avoidance of femininity components. H5a was not supported. Amount of viewing sitcoms was not associated with either the importance of $\operatorname{sex}(r=.07$, $n s)$ or the avoidance of femininity components $(r=-.03, n s)$ of the MRNI-R. Finally, H5b predicted that amount of viewing of sitcoms would be negatively correlated with endorsement of the negativity toward gay men and the restrictive emotionality components. H5b was also not supported in that amount of viewing of sitcoms was not associated with negativity toward gay men $(r=-.10, n s)$ or restrictive emotionality $(r=-.04, n s)$ in the data.

From the correlation analyses, therefore, we can conclude that genre viewing, on balance, rather than overall amount of television viewing was more strongly associated with endorsement of traditional masculine gender roles. Among genres, the viewing of police and detective programs and sports stood out for their positive associations with more traditional views of masculinity, in general, and reality television for its positive association with particular views of masculinity as including strong sexual drive and dominance. Viewing of sitcoms did not appear to relate to endorsement of masculine roles.

\section{Moderation analyses}

The Hayes PROCESS macro in SPSS (Hayes, 2013) was used to determine whether the associations tested in the above correlations were moderated by sex of respondent, as called for in H6. The PROCESS moderation analysis is based on ordinary least squares regression and provides a means of testing an interaction between a moderator (in this case, biological sex of respondent) and a predictor variable (in this case, various forms of television exposure) on an outcome (in this case, the MRNI-R and its various components). The use of PROCESS avoids the need to manually produce an interaction term and potentially account for its multicollinearity, and the resulting coefficients are interpreted as one would interpret an unstandardized Beta in a regression test (Hayes, 2012). Sexual orientation, race (both dummy coded), education, and income were entered as covariates in the moderation analyses. When the 
resulting interaction terms were significant, the results for the conditional effect of the predictor variable at each of the values of the dichotomous moderator provided by the PROCESS macro were used to visualize the interaction (Hayes, 2012).

Results showed that the interaction between biological sex and overall amount of television exposure was non-significant with both the MRNI-R and the aggression and physical violence component of the ADMI as outcome variables. Yet, overall amount of television exposure was a significant simple effects predictor (coefficient $=.15, S E=.06, t=2.40, p=.019)$ and the interaction between sex of respondent and overall exposure fell just short of the adapted significance level in predicting the negativity toward gay men component of the MRNI-R, in particular (coefficient $=-.09$, $S E=.04, t=-2.26, p=.024)$. The $r^{2}$ increase due to the interaction was $0.01, F(1,412)=5.12, p=.024$.

The next set of PROCESS moderation analyses explored genre-specific television exposure as the predictor, biological sex as the moderator, and each of the MRNI-related outcomes proposed in the hypotheses, with the same covariates as in the prior moderation analyses in addition to overall amount of television in order to isolate the statistical contribution of the genre. The interaction between amount of viewing sitcoms and sex of respondent was non-significant for negativity toward gay men and for restrictive emotionality. Yet, exposure to sitcoms did interact with sex of respondent to predict scores for avoidance of femininity (coefficient $=-.18, S E=.07, t=-2.48, p=.013$ ). The $r^{2}$ increase due to the interaction was $0.01, F(1,411)=6.17, p=.013$. Plotted visually, we found that for biological males, higher amounts of viewing of sitcoms was associated with slightly higher scores on avoidance of femininity, whereas for biological females, higher sitcom viewing was associated with lower scores (see Figure 1). Sitcom viewing and biological sex of respondent also interacted to predict scores on the importance of sex component (coefficient $=-.19, S E=.07, t=-2.53, p=.011$ ). The $r^{2}$ increase due to the interaction was $0.01, F(1,411)=6.38, p=.011$. For this component, higher levels of sitcom viewing 
were associated with higher scores for biological males, whereas scores on importance of sex were rather consistent across low and high sitcom viewing biological females in the sample (see Figure 2).

Figures 1 and 2 about here

Amount of viewing of reality television interacted with biological sex of respondent (coefficient $=-.17, S E=.05, t=-3.06, p=.002)$ to predict scores on the MRNI-R as a whole. The $r^{2}$ increase due to the interaction was $0.02, F(1,411)=9.37, p=.002$. In visualizing the interaction, we see that biological male heavy viewers of reality television had higher scores on the MRNI-R than biological female heavy viewers (see Figure 3). Regarding the individual components of the MRNI-R, viewing reality television interacted with sex of respondent in predicting scores on importance of sex $($ coefficient $=-.22, S E=$ $.07, t=-3.06, p=.003 ; r^{2}$ change $=0.02, F(1,411)=9.39, p=.003$; see Figure 4$)$ and dominance components $\left(\right.$ coefficient $=-.24, S E=.06, t=-3.84 ; p<.001 ; r^{2}$ change $=0.03, F(1,411)=14.74, p<$ .001 ; see Figure 5). Higher levels of reality TV viewing were associated with slightly higher scores among biological females as well as with much higher scores among biological males for both importance of sex and dominance (see Figures 4 and 5). Reality TV viewing neither exerted a simple effects influence nor interacted with sex in predicting scores on the aggression and physical violence component of the ADMI.

Figures 3, 4, and 5 about here

Biological sex of respondent and amount of police and detective program viewing did not interact to predict scores on the MRNI-R as a whole or the individual components hypothesized. Yet, 
police and detective viewing was a significant simple effects predictor of the MRNI-R (coefficient = $.25, S E=.09, t=2.68 ; p=.008)$. Finally, sports viewing did not interact with sex in predicting scores on either the MRNI-R or the aggression and physical violence component of the ADMI. Sports viewing, however, was also a simple effects predictor of the MRNI-R (coefficient $=.23, S E=.08, t=$ 2.94, $p=.004)$. Thus, viewing of police programs and sports displayed the same general pattern.

We can conclude from these analyses that the viewing of some genres-namely sitcoms and reality television — predicted endorsement of traditional views of masculine gender roles more strongly among biological male respondents compared to biological female respondents. On the other hand, police and detective program and sports viewing predicted endorsement of traditional views of masculine gender roles regardless of one's own sex, with results indicating simple rather than conditional effects. Therefore, H6, which predicted that the relationship between television viewing and endorsement of traditional masculine gender roles would be stronger for men compared to women, received partial support.

\section{Discussion}

Cultivation theory predicts that cumulative viewing of a stable message system results in a blurring of social reality with the version of reality presented on television (Gerbner \& Gross, 1976). Second-order judgments - those that are theorized to occur when viewers make judgments spontaneously by inferring from the available television message to their own values, attitudes, and conceptions (Shrum \& Lee, 2012) — demonstrate the ability of the cultural environment to spill over into views of the real world. Gender roles are an example of meta-level messages that have a broad presence in television programming (Morgan et al., 2015), and the current study examines what can be learned from those messages about masculine roles, in particular. We did not see consistent evidence that overall amount of television viewing predicted endorsement of traditional masculine gender roles in the national 
sample of emerging adult men and women in the data, as had been found in bivariate correlations among college males in prior research (Giaccardi et al., 2016, 2017). Yet, we did find considerable evidence that genre viewing, in particular, was associated with such views. Given that emerging adulthood is a critical period for formation of conceptions of masculinity (Marcell et al., 2011), and given the personally tailored ways in which modern television audiences encounter content (Morgan et al., 2015), the ability of genre viewing to contribute to endorsement of views of masculinity is an important finding.

In the present findings, there is evidence that the cultural environment provided by television storytelling within particular genres is associated with emerging adult viewers' conceptions of what masculine gender roles should entail. Different forms of television viewing positively related to either the Masculine Gender Roles Inventory-Revised as a whole or to particular components of the scale, with increased viewing associated with stronger endorsement of traditional views of masculine gender roles. Thus, we speculate that television has the potential to contribute to gender stereotypes regarding masculine gender roles, as has been found in prior studies regarding feminine roles (Kahlor \& Morrison, 2007; Morgan \& Shanahan, 1997; Oppliger, 2007). Holding such views can be seen as hegemonic in that power and dominance are reinscribed to particular performances of masculinity (Connell, 2005; Connell \& Messerschmidt, 2005; Kimmel, 1987).

Tests of cultivation theory over time have challenged and/or broken away from some of the original assumptions and premises of the theory as put forth by George Gerbner and colleagues (Gerbner $\&$ Gross, 1976) to such a degree that some have questioned whether recent applications of the theory should be considered cultivation at all (Morgan et al., 2014; Potter, 2014). Applying the logic laid out by Potter (2014), the current study stays true to some features of the original theory by examining the role of overall amount of television viewing in constructing individuals' outlooks and by relying on content analysis evidence of the features of the "message system" in making those predictions. In keeping with 
the majority of the evidence for cultivation, the magnitude of the statistical associations found in the current study is small to moderate (Morgan et al., 2014; Potter, 2014). Yet, the biggest departure from original cultivation premises is the exploration of genre viewing alongside overall amount of viewing, a move that Potter (2014) characterizes as a shift from a macro- to a microlevel of analysis. This study joins others in finding stronger evidence for genre-based viewing associations with respondents' views of social reality compared to associations with overall viewing (Cohen \& Weimann, 2000; Morgan et al., 2015), even when controlling for overall viewing.

The current data support prior research that shows sports viewing, in particular, predicts endorsement of traditional views of masculine gender roles (Giaccardi et al., 2016, 2017; Johnson \& Schiappa, 2010). Prior evidence that sports programming is a site of aggression, toughness, dominance, and avoidance of femininity among males (Dutta-Bergman \& Dutta-Bergman, 2005; Hust et al., 2013) is likely to account for the sizeable correlations in the present data among the entire sample between sports viewing and the MRNI-R as well as the aggression and physical violence scale. In fact, although bivariate statistics showed biological males viewed sports on television more often than biological females in the sample, respondent sex did not moderate associations between sports viewing and the MRNI-R, suggesting that messages about masculinity are received consistently across different levels of sports TV exposure as well among viewers of both biological sexes. Further, since biological sex and gender identity were closely matched among those in the sample, we can, for the most part, extend this conclusion to gender identity, as well (as is the case for each similar analysis). Because sports genre viewing produced the largest magnitude of associations with traditional conceptions of masculine gender role norms, we speculate that the gender stereotypical content of sports programming regarding masculinity is so robust that male and female viewers interpret it similarly, as do relatively heavy and light viewers of the genre. 
The present results both support and extend beyond prior findings regarding the role of reality TV viewing in predicting endorsement of dominant or traditional masculinity (Giaccardi et al., 2016, 2017). We identify particular conceptions pertaining to masculinity that are associated with viewing reality TV among both biological men and women in emerging adulthood in the sample, the importance of sex and dominance components of the MRNI-R. These findings are likely to stem from the evidence that suggests men in reality TV programs frequently exhibit behaviors that emphasize sexual drive and conquest that place them in dominant positions over women in heterosexual relationships (Ferris et al., 2007; Giaccardi et al., 2016; Rivadeneyra \& Lebo, 2008; Zurbriggen \& Morgan, 2007). We also find that sex of respondent moderates the relationship between reality television viewing and endorsement of the importance of sex and dominance as salient aspects of dominant masculine gender roles, with stronger associations among biological male compared to female respondents. This pattern supports the cultivation theory explanation that second-order judgments in which viewers infer from television messages to their own values and beliefs are more likely to be made when viewers perceive the topic to be personally relevant (Schnauber \& Meltzer, 2016; Shrum \& Lee, 2012). We assume that biological male respondents perceived the messages apparent in the genre about masculine gender roles as more relevant than biological female respondents, since they are the members of the social group in question, and thereby exhibited a stronger association between viewing reality TV and believing that sexual drive and conquest as well as dominance are important elements of masculinity. We speculate further that the variation within reality TV content (Edwards, 2013) allows for the differential susceptibility by biological sex that we see in the findings. Such interpretations appear to be made independently of frequency of viewing, since biological male respondents had stronger associations between reality TV viewing and endorsement of the importance of sex and dominance components in the current data despite the finding that biological female respondents viewed the genre significantly more often. 
Extending beyond the genres explored in prior research, the present study finds new evidence that viewing of police and detective programs predicts views of toughness, physical aggression, and restrictive emotionality as endorsed elements of traditional masculinity among both biological male and female viewers. This is perhaps not surprising given that male characters in cop shows often engage in violence (Finger, et al., 2010; Parrott \& Parrott, 2015; Scharrer, 2012) and are relatively emotionally stoic (Scharrer, 2012). As with the other genre for which we found simple rather than conditional effects (sports), we speculate here that the content in police and detective programs sends a consistent message to viewers regarding which masculine gender roles are presented as normative or ideal.

We also provide new data about the role of sitcom viewing in predicting endorsement of traditional masculinity. Despite prior evidence that sitcoms tend to present male characters in stereotypical roles (Kim, et al., 2007; Montemurro, 2003; Scharrer, 2001), some views of masculine norms were not associated with sitcom viewing at all in the data and other views were received quite differently by biological male and female viewers. Among biological female respondents, heavy sitcom viewing was associated with lower endorsement whereas among biological male respondents heavy sitcom viewing was associated with higher endorsement of avoidance of femininity as a key aspect of endorsed masculine gender roles. Similarly, heavy sitcom viewing biological males had higher endorsement of the importance of sex aspect of masculine gender roles compared to heavy sitcom viewing biological females. Given the complexities of humor likely to be operating in sitcom content, including parody and satire (Lieberman et al., 2009), we speculate that sitcoms may be interpreted differently by viewers of different sexes regarding their messages about masculinity.

There are certainly limitations to the current study that the reader should consider when interpreting its results. First, although we have employed a national sample that reflects the racial and ethnic composition of the United States, potential respondents were randomly selected from the 
Qualtrics database not from the U.S. population at large and data collection ended when the requested number of participants was satisfied. It is possible, therefore, that those who responded to the request early self-selected based on interest (or were otherwise unique in some way) compared to others. Second, although it is in line with the methods of Giaccardi and colleagues $(2016,2017)$, the fact that we measured viewing of reality television as an undifferentiated, generalized category obfuscates the considerable variation within programs that fit underneath that umbrella term. Indeed, much of the prior evidence on which we based our hypothesis (Ferris et al., 2007; Rivadeneyra \& Lebo, 2008; Zurbriggen \& Morgan, 2007) examined a subset of reality television programs focused particularly on romance and dating. It is possible that a more specific measure of a subset of reality TV would have produced different results. Third, we have examined only some of many possible television genres. Other genres certainly exist that may bear on audience members' formation of beliefs and attitudes regarding masculinity. Fourth, the cross-sectional nature of the present survey design prevents any conclusions regarding causality and fails to reject the possibility that respondents' views of masculinity might cause them to watch particular types or amount of television rather than (or in addition to) particular types or amounts of television causing respondents to form views of masculinity. Finally, despite our use of a widely established index, any attempt to measure the concept of masculinity is likely to be only partially responsive to complex understandings of the term. Regarding our uses of the words "dominant" and "traditional," for instance, one might wonder dominant or traditional for whom or by what standards?

Future research should explore whether and how satire, parody, and comedy in general might help determine the process by which viewers make second-order cultivation judgments regarding the messages about masculinity presented through the sitcom genre. It should also isolate particular subgenres of reality television programming to locate specific messages about masculinity that viewers may glean from the programs' content. Future research should employ longitudinal survey design to 
attempt to parse the directionality of the associations measured in the current study, and to test the possibility that viewers learn about gender normative roles cumulatively over time. Given the indication in the current study that viewing of particular types of television is linked to the endorsement of relatively narrow beliefs about what masculine gender roles should entail in ways that may affect the day-to-day lives of many, the topic is worthy of additional social science inquiry. 


\section{References}

Arntfield, M. (2011). TVPD: The generational diegetics of the police procedural on American television. Canadian Review of American Studies, 41(1), 75-95. doi: 10.3138/cras.41.1.75.

Barron, J.M., Struckman-Johnson, C., Quevillon, R., \& Banka, S.R. (2008). Heterosexual men's attitudes toward gay men: A hierarchical model including masculinity, openness, and theoretical explanations. Psychology of Men and Masculinity, 9(3), 154-166. doi: 10.1037/15249220.9.3.154.

Benjamini, Y., \& Hochberg, Y. (1995). Controlling the false discovery rate: a practical and powerful approach to multiple testing. Journal of the Royal Statistical Society, Series B (Methodological), 57(1), 289-300.

Bilandzic, H., \& Busselle, R.W. (2008). Transportation and transportability in the cultivation of genreconsistent attitudes and estimates. Journal of Communication, 58, 508-529. doi: 10.1111/j.14602466.2008.00397.x.

Bilandzic, H., \& Busselle, R. (2012). A narrative perspective on genre-specific cultivation. In M. Morgan, J. Shanahan, \& N. Signorielli (Eds.), Living with television now: Advances in cultivation theory \& research (pp. 261-285). New York, NY: Peter Lang.

Bilandzic, H., \& Rössler, P. (2004). Life according to television. Implications of genre-specific cultivation effects: The Gratification/Cultivation model. Communications: The European Journal of Communication Research, 29(3), 295-236. doi: 03412059/2004/029-0295.

Bond, B.J. (2014). Sex and sexuality in entertainment media popular with lesbian, gay, and bisexual adolescents. Mass Communication \& Society, 17, 98-120. doi: 10.1080/15205436.2013.816739.

Burk, L.R., Burkhart, B. R., \& Sikorski, J. F. (2004). Construction and preliminary validation of the Auburn Differential Masculinity Inventory. Psychology of Men \& Masculinity, 5(1), 4-17. doi: 
10.1037/1524-9220.5.1.4.

Calzo, J. P., \& Ward, L. M. (2009). Media exposure and viewers' attitudes toward homosexuality: Evidence for mainstreaming or resonance? Journal of Broadcasting \& Electronic Media, 53, 280-299. doi: 10.1080/08838150902908049.

Chonody, J. W. (2013). Measuring sexual prejudice against gay men and lesbian women: Development of the sexual prejudice scale (SPS). Journal of Homosexuality, 60(6), 895-926. doi: 10.1080/00918369.2013.774863.

Cohen, J., \& Weimann, G. (2000). Cultivation revisited: Some genres have some effects on some viewers. Communication Reports, 13(2), 99-115. doi:10.1080/08934210009367728.

Connell, R. W. (2005). Masculinities. Berkley: University of California Press.

Connell, R.W., \& Messerschmidt, J.W. (2005). Hegemonic masculinity: Rethinking the concept. Gender and Society, 19(6), 829-859. doi: 10.1177/0891243205278639.

Costello, A.B., \& Osborne, J.W. (2005). Best practices in exploratory factor analysis: Four recommendations for getting the most from your analysis. Practical Assessment, Research, and Evaluation, 10(7), 1-9. Accessed 8/31/17 at http://pareonline.net/getvn.asp?v=10\&n=7.

Dutta-Bergman, M., \& Dutta-Bergman, A. (2005, May). The consumption of media types and attitudes toward gender equity: A population-based study. Paper presented at the annual meeting of the International Communication Association, New York, NY.

Edwards, L. H. (2013). The triumph of reality TV: The revolution in American television. Santa Barbara, CA: Praeger.

Feasey, R. (2008). Masculinity and popular television. Edinburgh, GBR: Edinburgh University Press.

Ferris, A.L., Smith, S.W., Greenberg, B. S., \& Smith, S. L. (2007). The content of reality dating shows and viewer perceptions of dating. Journal of Communication, 57, 490-510. doi:10.1111/j.1460- 
2466.2007.00354.x.

Finger, J., Unz, D. C., \& Schwab, F. (2010). Crime scene investigation: The chief inspectors' display rules. Sex Roles, 62, 98-809. doi: 10.1007/s11199-009-9722-5.

Fisher, D. A., Hill, D. L., Grube, J. W., \& Gruber, E. L. (2007). Gay, lesbian, and bisexual content on television. Journal of Homosexuality, 52(3-4), 167-188. doi: 10.1300/J082v52n03_08.

Fowler, K. \& Thomas, V. (2015). A content analysis of male roles in television advertising: Do traditional roles still hold? Journal of Marketing Communications, 21(5), 356-371. doi: 10.1080/13527266.2013.775178.

Gerbner, G. (2002a). The importance of being critical—in one's own fashion. In M. Morgan (Ed.), Against the mainstream: The selected works of George Gerbner (pp. 409-415). New York: Peter Lang.

Gerbner, G. (2002b). On content analysis and critical research in mass communication. In M. Morgan (Ed.), Against the mainstream: The selected works of George Gerbner (pp. 62-87). New York: Peter Lang.

Gerbner, G., \& Gross, L. (1976). Living with television: The violence profile. Journal of Communication, 26(2), 173-199. doi: 10.1111/j.1460-2466.1976.tb01397.x.

Gerbner, G., Gross, L., Morgan, M., \& Signorielli, N. (1980). The mainstreaming of America: Violence profile no. 11. Journal of Communication, 30(3), 10-29. doi:10.1111/j.14602466.1980.tb01987.x.

Giaccardi, S., Ward, L. M., Seabrook, R. C., Manago, A., \& Lippman, J. (2016). Media and modern manhood: Testing associations between media consumption and young men's acceptance of traditional gender ideologies. Sex Roles, 1-13. doi: 10.1007/s11199-016-0588-z.

Giaccardi, S., Ward, L.M., Seabrook, R.C., Manago, A., \& Lippman, J. (2017). Media use and men's 
risk behaviors: Examining the role of masculine ideology. Sex Roles, doi:10.1007/s11199-0170754-y.

Gramsci, A. (1971). Selections from the prison notebooks. New York, NY: International Publishers.

Grauerholz, E., \& King, A. (1997). Prime time sexual harassment. Violence against Women, 3, 129-148. doi: $10.1177 / 1077801297003002003$.

Greenberg, B. S., Eastin, M. S., Skalski, P., Cooper, L., Levy, M., \& Lachlan, K. (2005). Comparing survey and diary measures of internet and traditional media use. Communication Reports, 18, 18. doi:10.1080/08934210500084164.

Hanke, R. (1992). Redesigning men: hegemonic masculinity in tradition. In S. Craig (Ed.), Men, masculinity, and the media (pp. 185-189). Newbury Park, CA: Sage.

Hayes, A. F. (2012). PROCESS: A versatile computational tool for observed variable mediation, moderation, and conditional process modeling [White paper]. Retrieved 6/7/17 from http://www.afhayes.com/ public/process2012.pdf.

Hayes, A.F. (2013). Introduction to mediation, moderation, and conditional process analysis: A regression-based approach. New York: The Guilford Press.

Hirsch, P. M. (1981). On not learning from one's own mistakes: A reanalysis of Gerbner et al.'s findings on cultivation analysis Part II. Communication Research, 8, 3-37.

Hust, S. J. T., Lei, M., Ren, C., Chang, H., McNab, A. L., Marett, E. G., \& Willoughby, J. F. (2013). The effects of sports media exposure on college students' rape myth beliefs and intentions to intervene in a sexual assault, Mass Communication and Society, 16(6), 762-786. doi: 10.1080/15205436.2013.816737.

Johnson, T.C., \& Schiappa, E. (2010). An exploratory study of the relationships between televised sports viewing habits and conformity to masculine norms. Journal of Sports Media, 5(1), 53-78. doi: 
10.1353/jsm.0.0045.

Kahlor, L. A., \& Morrison, D. (2007). Television viewing and rape myth acceptance among college women. Sex Roles, 56(11/12), 729-739.

Kim., J. L., Sorsoli, C. L., Collins, K., Zylbergold, B. A., Schooler, D., \& Tolman, D. L. (2007). From sex to sexuality: Exposing the heterosexual script on primetime network television. Journal of Sex Research, 44(2), 145-157. doi: 10.1080/00224490701263660.

Kimmel, M. S. (1987). Rethinking "masculinity": New directions in research. In M. Kimmel (Ed.), Changing men: New directions in research on men and masculinity (pp.9-24). Newbury Park, CA: Sage.

Kuo, P.X., \& Ward, L.M. (2016). Contributions of television use to beliefs about fathers and gendered family roles among first-time expectant parents. Psychology of Men \& Masculinity. Advance online publication. http://dx.doi.org/10.1037/men0000033.

Lauzen, M. M., \& Dozier, D. M. (2002). You look mahvelous: An examination of gender and appearance comments in the 1999-2000 prime-time season. Sex Roles, 46(11/12), 429-437. doi: 10.1023/A:1020417731462.

Lauzen, M.M., Dozier, D.M., \& Horan, N. (2008). Constructing gender stereotypes through social roles on primetime television. Journal of Broadcasting \& Electronic Media, 52, 200-214. doi: 10.1080/08838150801991971.

Levant, R. F., \& Richmond, K. (2007). A review of research on masculinity ideologies using the male role norms inventory. The Journal of Men's Studies, 15(2), 130-146. doi: 10.3149/jms.1502.130.

Levant, R. F., Smalley, K. B., Aupont, M., House, A. T., Richmond, K., \& Noronha, D. (2007). Initial validation of the Male Role Norms Inventory-Revised (MRNI-R). The Journal of Men's Studies, 15(1), 83-100. doi: 10.3149/jms.1501.83. 
Levant, R. F., Rankin, T. J., Williams, C. M., Hasan, N. T., \& Smalley, K. B. (2010). Evaluation of the factor structure and construct validity of scores on the Male Role Norms Inventory-Revised (MRNI-R). Psychology of Men and Masculinity, 11(1), 25-37. doi: 10.1037/a0017637.

Lieberman, E.A., Neuendorf, K.A., Denny, J., Skalski, P.D., \& Wang, J. (2009). The language of laughter: A quantitative/qualitative fusion examining television narrative and humor. Journal of Broadcasting and Electronic Media, 53(4), 497-514. doi: 10.1080/08838150903336141.

Marcell, A. V., Eftim, S. E., Sonenstein, F. L., \& Pleck, J. H. (2011). Associations of family and peer experiences with masculinity attitude trajectories at the individual and group level in adolescent and young adult males. Men and Masculinities, 14(5), 565-587. doi:10.1177/1097184X11409363.

Miller, B. \& Lewallen, J. (2015). The effects of portrayals of gay men on homonegativity and the attribution of gender-based descriptors. Communication Studies, 66(3), 358-377. doi: 10.1080/10510974.2015.1018446.

Montemurro, B. (2003). Not a laughing matter: Sexual harassment as "material” on workplace-based situation comedies. Sex Roles, 48(9/10), 433-445. doi: 10.1023/A:1023578528629.

Morgan, M. (1982). Television and adolescents' sex role stereotypes: a longitudinal study. Journal of Personality and Social Psychology, 43(5), 947-955. doi: 10.1037/0022-3514.43.5.947.

Morgan, M. (2009). Cultivation analysis and media effects. In R. Nabi \& M. Oliver (Eds.), The SAGE handbook of media processes and effects (pp. 69-82). Los Angeles: Sage Publications.

Morgan, M., \& Shanahan, J. (1997). Two decades of cultivation research: An appraisal and metaanalysis. In B. Burleson (Ed.) Communication yearbook 20 (pp. 1-45). Thousand Oaks, CA: Sage.

Morgan, M., Shanahan, J., \& Signorielli, N. (2012). Looking forward, looking backward: Ten questions about cultivation. In M. Morgan, J. Shanahan, \& N. Signorielli (Eds.), Living with television now. 
Advances in cultivation theory and research (pp. 389-404). New York: Lang.

Morgan, M., Shanahan, J., \& Signorielli, N. (2015). Yesterday's new cultivation, tomorrow. Mass Communication and Society, 18, 674-699. doi: 10.1080/15205436.2015.1072725.

Oppliger, P.A. (2007). Effects of gender stereotyping on socialization. In R.W. Preiss, B.M. Gayle, N. Burrell, M. Allen, \& J. Bryant (Eds.), Mass media effects research: Advances through metaanalysis (pp. 199-214). Mahwah, NJ: Lawrence Erlbaum.

Parrott, S., \& Parrott, C.T. (2015). U.S. television's “mean world" for White women: The portrayal of gender and race on fictional crime dramas. Sex Roles, 73(1/2), 70-82. doi: 10.1007/s11199-0150505-x.

Potter, W.J. (1993). Cultivation theory and research: A conceptual critique. Human Communication Research, 19, 564-601.

Potter, W.J. (2014). A critical analysis of cultivation theory. Journal of Communication, 64, 1015-1036. doi: $10.1111 /$ jcom.12128.

Prieler, M. (2016). Gender stereotypes in Spanish- and English-language television advertisements in the United States. Mass Communication \& Society, 19, 275-300. doi: $10.1080 / 15205436.2015 .1111386$.

Raley, A. B., \& Lucas, J. L. (2006). Stereotype or success? Prime-time television's portrayals of gay male, lesbian, and bisexual characters. Journal of Homosexuality, 51(2), 19-38. doi: 10.1300/J082v51n02_02.

Rivadeneyra, R. \& Lebo, M. J. (2008). The association between television-viewing behaviors and adolescent dating role attitudes and behaviors. Journal of Adolescence, 31, 291-305. doi:10.1016/j.adolescence.2007.06.001.

Rivadeneyra, R., \& Ward, L. M. (2005). From Ally McBeal to Sabado Gigante: Contributions of 
television viewing to the gender role attitudes of Latino adolescents. Journal of Adolescent Research, 20, 453-475. doi: 10.1177/0743558405274871.

Robinson, J. P., \& Godbey, G. (1997). Time for life: The surprising ways Americans use their time. University Park: Pennsylvania State University Press.

Ruddock, A. (2001). Understanding audiences. Thousand Oaks, CA: Sage.

Scharrer, E. (2001). From wise to foolish: The portrayal of the sitcom father, 1950s-1990s. Journal of Broadcasting \& Electronic Media, 45(1), 23-40.

Scharrer, E. (2005). Hypermasculinity, aggression, and television violence: An experiment. Media Psychology, 7, 353-376. doi: 10.1207/S1532785XMEP0704_3.

Scharrer, E. (2012). More than "just the facts"?: Portrayals of masculinity in police and detective programs over time. The Howard Journal of Communications, 23, 88-109. doi: 10.1080/10646175.2012.641882.

Scharrer, E., Kim, D. D., Lin, K., \& Liu, Z. (2006). Working hard or hardly working? Gender, humor, and the performance of domestic chores in television commercials. Mass Communication \& Society, 9(2), 215-238. doi:10.1207/s15327825mcs0902_5.

Schiappa, E., Gregg, P. B., \& Hewes, D. E. (2006) Can one TV show make a difference? Will \& Grace and the parasocial contact hypothesis. Journal of Homosexuality, 51(4), 15-37. doi: 10.1300/J082v51n04_02.

Schnauber, A., \& Meltzer, C. (2016). On the distinction and interrelation between first- and second-order judgments in cultivation research. Communications: The European Journal of Communication Research, 41, 121-143. doi:10.1515/commun-2016-0004.

Shrum, L. J. (2004). The cognitive processes underlying cultivation effects are a function of whether the judgments are on-line or memory-based. Communications, 29, 327-344. 
doi:10.1515/comm.2004.021.

Shrum, L.J., \& Bischak, V.D. (2001). Mainstreaming, resonance, and impersonal impact: Testing moderators of the cultivation effect for estimates of crime risk. Human Communication Research, 27(2), 187-215.

Shrum, L. J., \& Lee, J. (2012). Multiple processes underlying cultivation effects: How cultivation works depends on the types of beliefs being cultivated. In M. Morgan, J. Shanahan, \& N. Signorielli (Eds.), Living with television now. Advances in cultivation theory and research (pp. 147-167). New York: Lang.

Signorielli, N. (1989). Television and conceptions about sex roles: Maintaining conventionality and the status quo. Sex Roles, 21(5/6), 341-360. doi: 10.1007/BF00289596.

Signorielli, N. (2003). Prime-time violence 1993-2001: Has the picture really changed? Journal of Broadcasting \& Electronic Media, 47(1),36-57. doi:10.1207/s15506878jobem4701_3.

Signorielli, N. (2009). Race and sex in primetime: A look at occupations and occupational prestige. Mass Communication and Society, 12, 332-352. doi: 10.1080/15205430802478693.

Sink, A., \& Mastro, D. (2017). Depictions of gender on primetime television: A quantitative content analysis. Mass Communication \& Society, 20(1), 3-22. doi: 10.1080/15205436.2016.1212243.

Smiler, A.P., \& Gelman, S.A. (2008). Determinants of gender essentialism in college students. Sex Roles, 58, 864-874. doi: 10.1007/s11199-008-9402-x.

Ter Bogt, T. F. M., Engels, R. C. M. E., Bogers, S., \& Kloosterman, M. (2010). "Shake it baby, shake it": Media preferences, sexual attitudes and gender stereotypes among adolescents. Sex Roles, 63, 844-859. doi: 10.1007/s11199-010-9815-1.

Vandenbosch, L., \& Eggermont, S. (2012). Maternal attachment and television viewing in adolescents’ sexual socialization: Differential associations across gender. Sex Roles, 66, 38-52. doi: 
10.1007/s11199-011-0075-5.

Verhellen, Y., Dens, N. \& de Pelsmacker, P. (2016). A longitudinal content analysis of gender role portrayal in Belgian television advertising. Journal of Marketing Communications, 22(2), 170188. doi: 10.1080/13527266.2013.871321.

Ward, L. M. (2003). Understanding the role of entertainment media in the sexual socialization of American youth: A review of empirical research. Developmental Review, 23, 347-388. doi:10.1016/S0273-2297(03)00013-3.

Ward, L. M., \& Friedman, K. (2006). Using TV as a guide: Associations between television viewing and adolescents' sexual attitudes and behavior. Journal of Research on Adolescence, 16, 133-156. doi: 10.1111/j.1532-7795.2006.00125.x.

Zimdars, M. (2017). Having it both ways: Two and a Half Men, Entourage, and televising post-feminist masculinity. Feminist Media Studies. doi: 10.1080/14680777.2017.1308411.

Zurbriggen E. L., \& Morgan, E. M. (2007). Who wants to marry a millionaire? Reality dating television programs, attitudes toward sex, and sexual behaviors. Sex Roles, 54(1/2), 1-17. doi: 
${ }^{1}$ A factor analysis (principal component analysis) with varimax rotation requesting a 7-factor solution confirmed that most of the items loaded cleanly to form factors comprising the subscales of the MRNI-R in the current data. Factor loadings for the items comprising the negativity toward gay men component ranged from .70 to .90 ; restrictive emotionality from .58 to .73 ; self-reliance .76 to .82 ; avoidance of femininity .52 to .63 ; and importance of sex .68 to .76 . Five of the 7 items comprising the dominance component loaded cleanly (.51 to .69), but the remaining two items ("A man should always be the major provider in his family;" and "Men should provide the discipline in the family;") loaded slightly higher with the self-reliance than with the dominance component (.46 compared to .41 , and .50 compared to .42 , respectively). Three of the 4 items comprising the toughness factor loaded cleanly (.44 to .67), but the fourth item ("It is important for a man to take risks, even if he might get hurt") produced a lower factor loading of .29 .

Overall, the results fit the criteria for a clean factor structure, with item loadings over .30 (38 of 39 items met this criterion, the one exception is noted directly above), few items crossloading (just 2 of 39 , again, as noted above), and no factors with fewer than three items (Costello \& Osborne, 2005). 
Table 1. Partial correlations for amount of viewing of television genres and the Masculine Role Norms Inventory-Revised as a whole, its individual components, and the Aggression and Physical Violence component of the Auburn Differential Masculinity Index (as hypothesized), controlling for overall amount of television viewing. Endorsement of traditional masculine gender roles

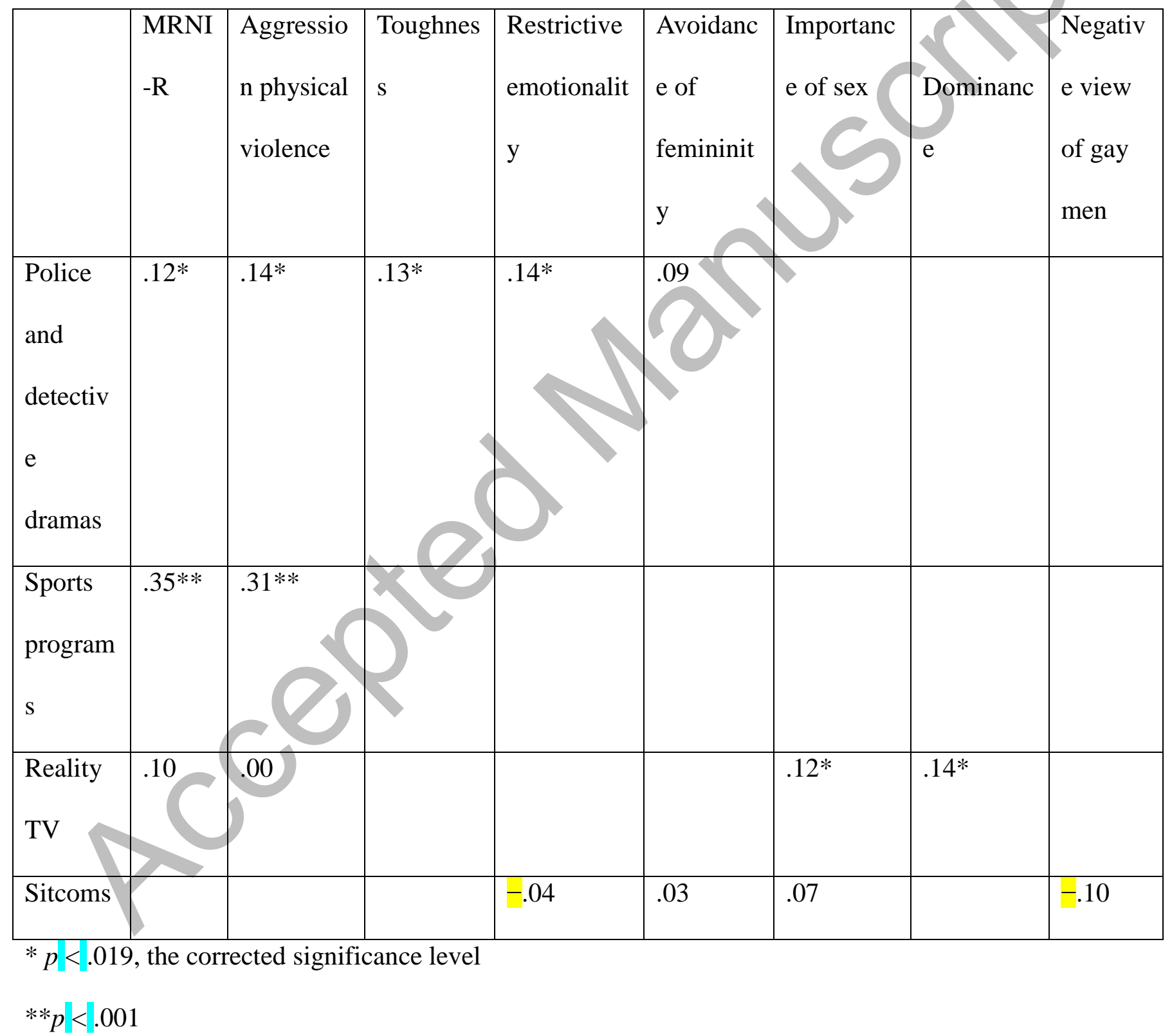


Figure 1. Interaction of amount of sitcom viewing and biological sex of respondent predicting the avoidance of femininity component of the MRNI-R, with demographic variables and overall amount of television viewing as covariates.

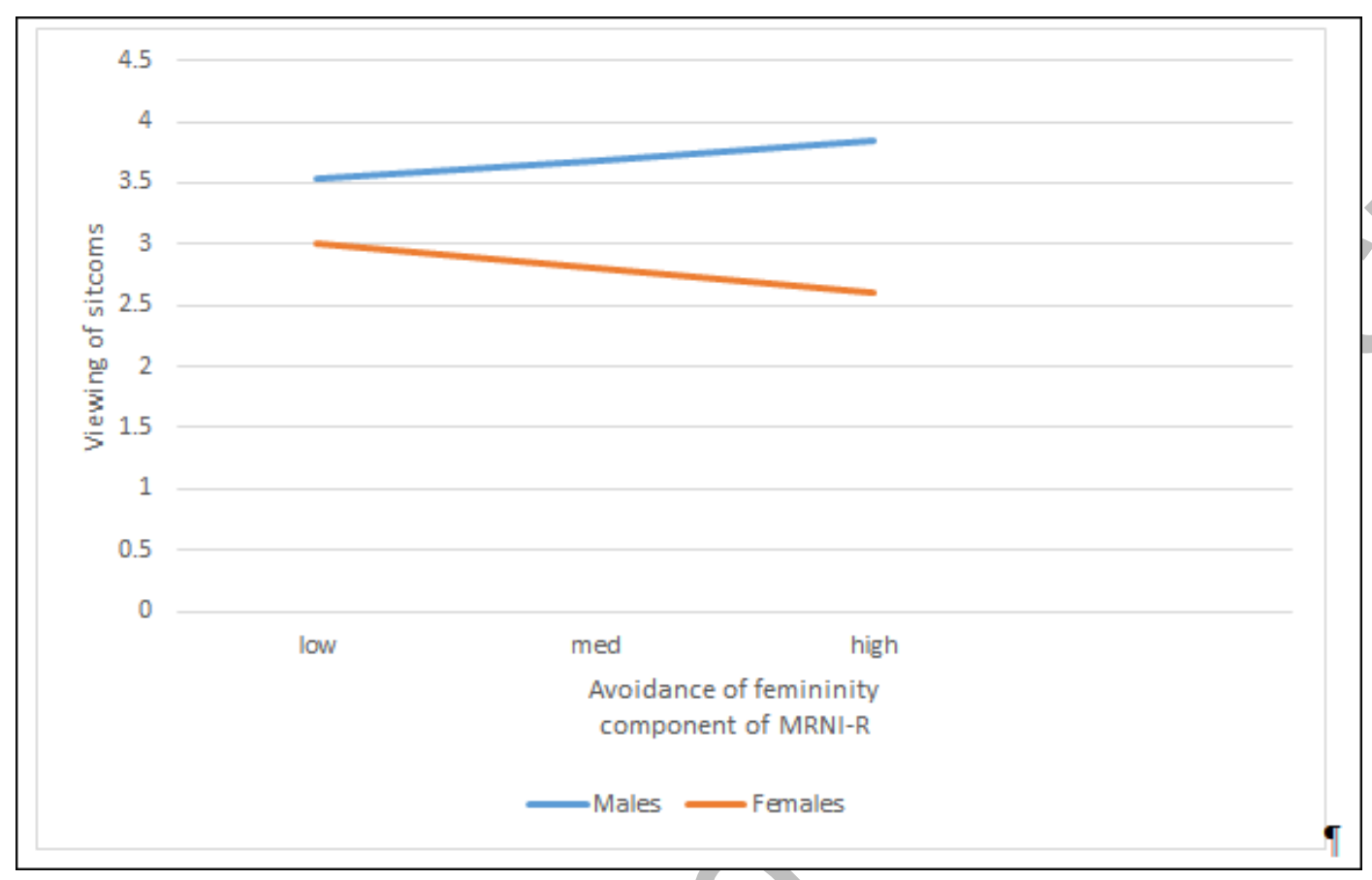


Figure 2. Interaction of amount of sitcom viewing and biological sex of respondent predicting the importance of sex component of the MRNI-R, with demographic variables and overall amount of television viewing as covariates.

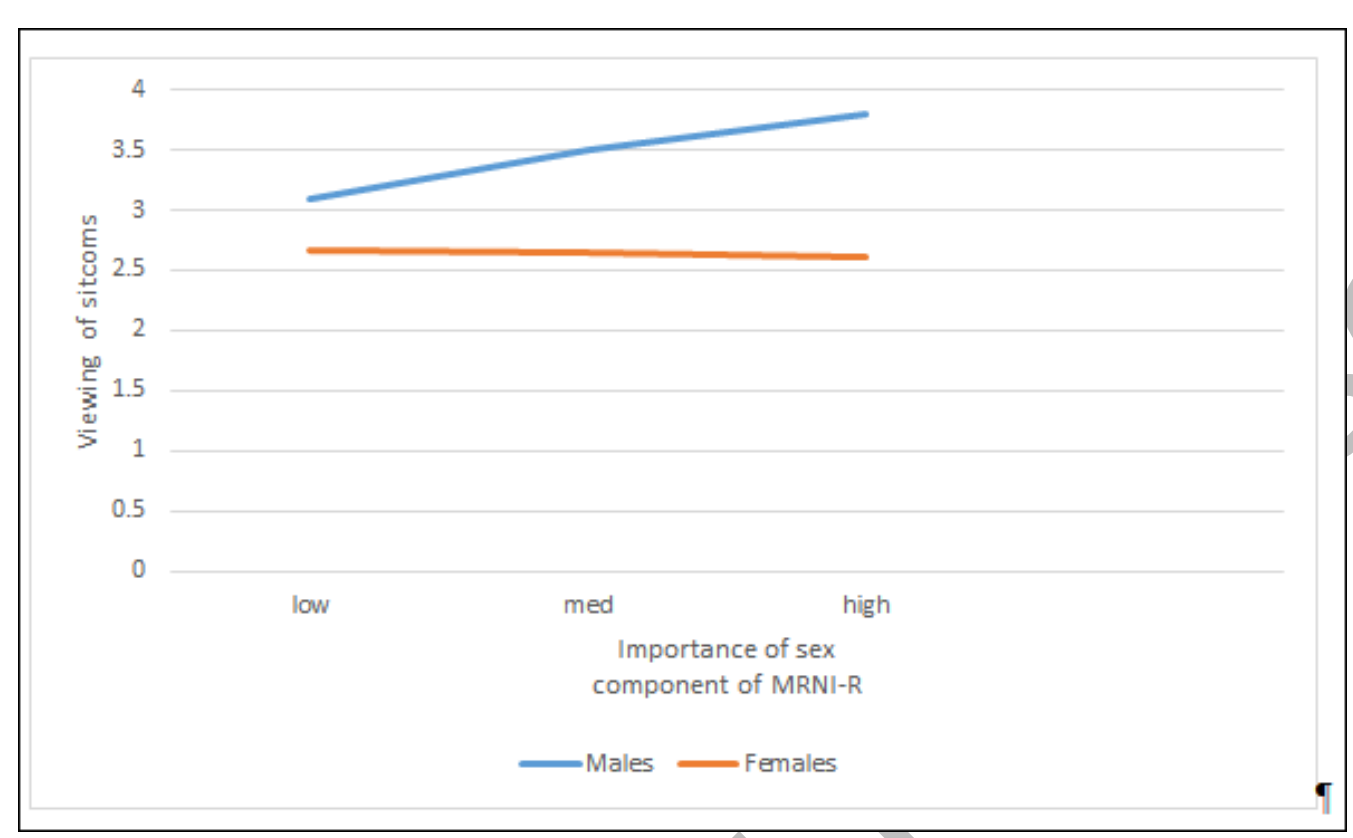


Figure 3. Interaction of amount of reality television viewing and biological sex of respondent predicting the MRNI-R, with demographic variables and overall amount of television viewing as covariates.

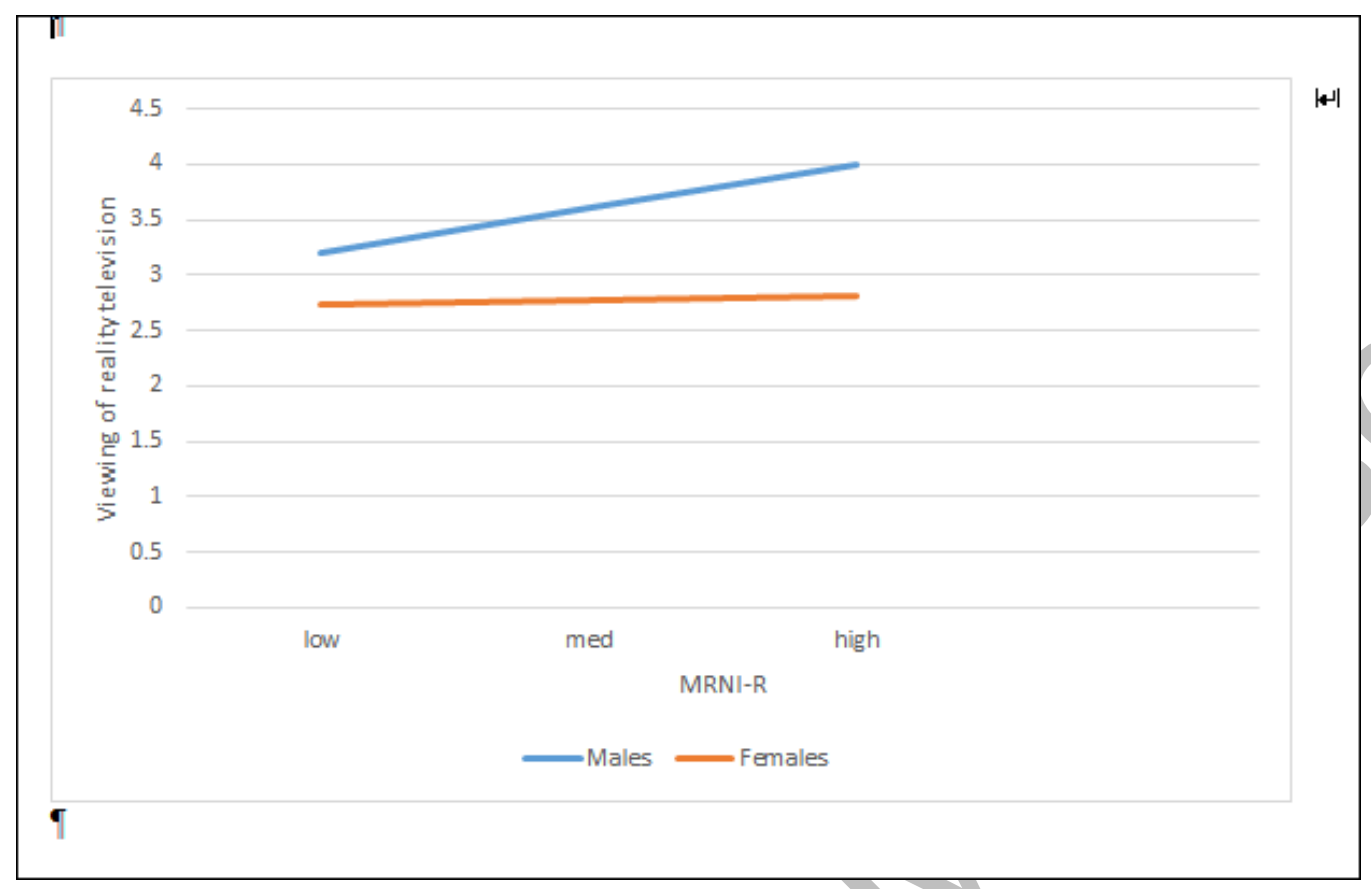


Figure 4. Interaction of amount of reality television viewing and biological sex of respondent predicting the dominance component of the MRNI-R, with demographic variables and overall amount of television viewing as covariates.

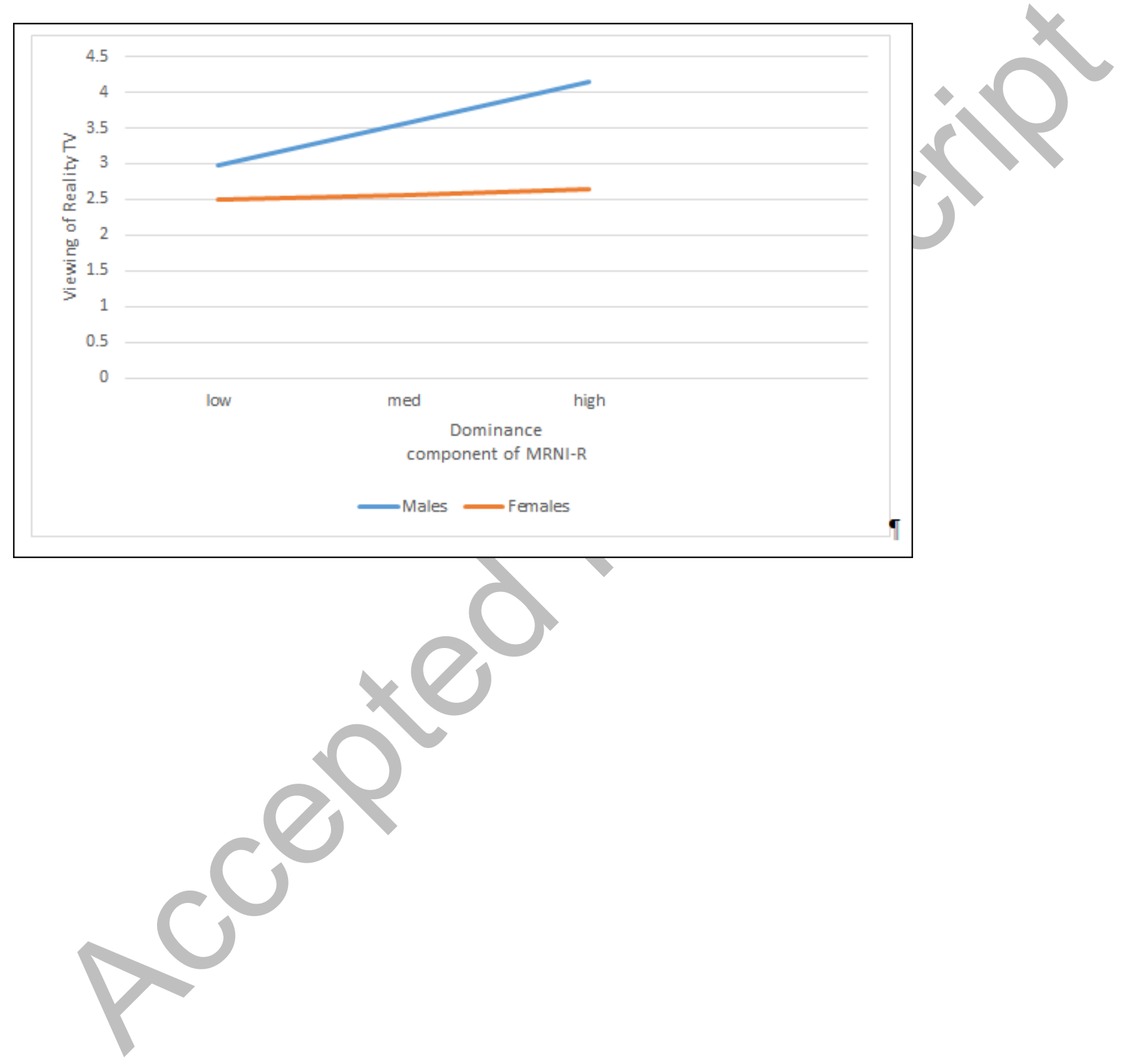


Figure 5. Interaction of amount of reality television viewing and biological sex of respondent predicting the importance of sex component of the MRNI-R, with demographic variables and overall amount of television viewing as covariates.

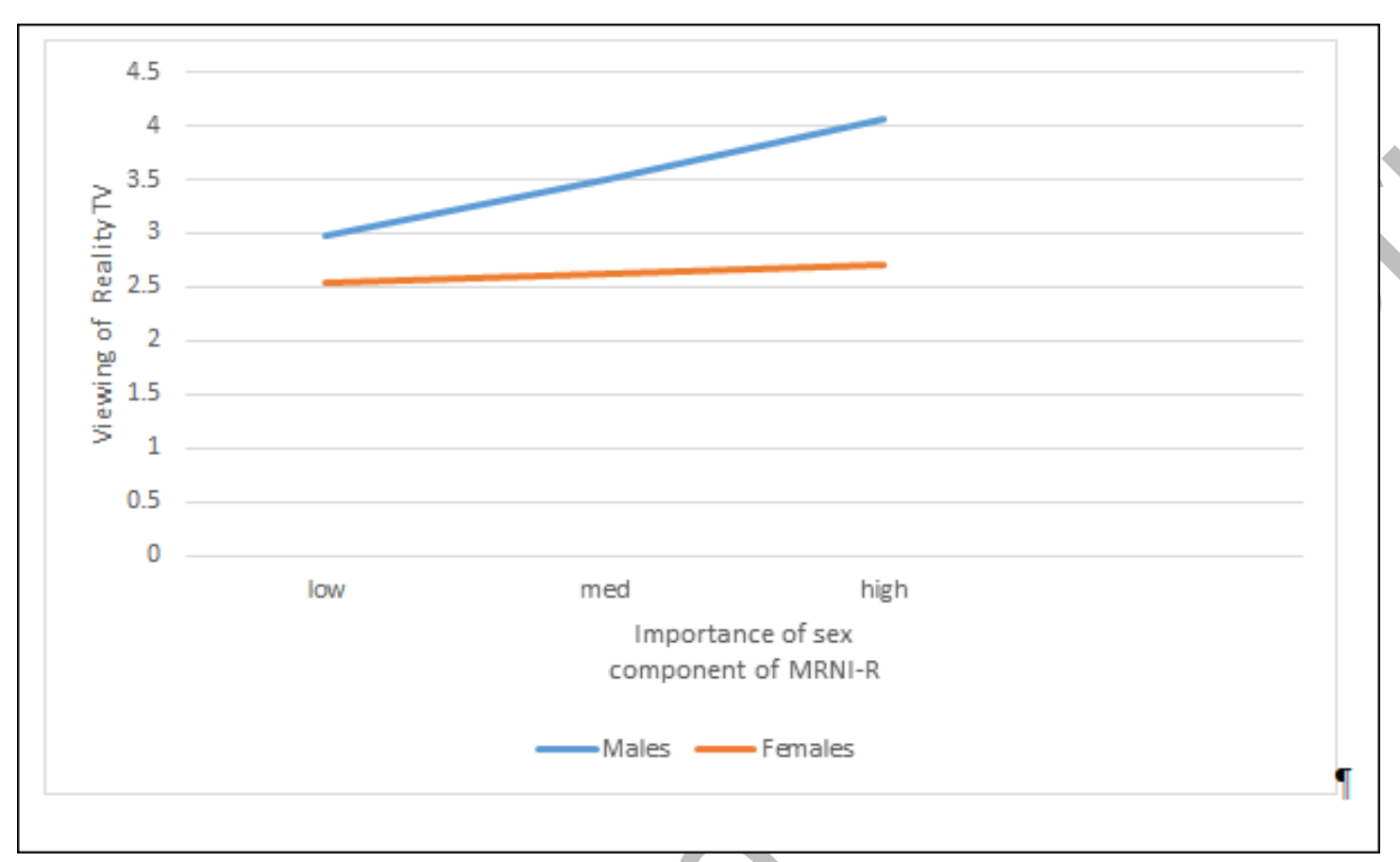

